\author{
International Journal of Innovative Research in \\ Electrical, Electronics, Instrumentation and Control Engineering
}

Vol. 9, Issue 12, December 2021

DOI: 10.17148/IJIREEICE.2021.91206

\title{
Abiding Drone: Onboard power generation in UAV
}

\author{
S Manush Maran ${ }^{1}$, D Jahnavi ${ }^{2}$, Mipham Jigmet ${ }^{3}$, Dharshini Devi ${ }^{4}$, Sivaraman $^{5}$ \\ 1, 2, 3, ${ }^{4}$ B.E. Aeronautical Engineering, Hindusthan College of Engineering and Technology, \\ Coimbatore, Tamil Nadu, India \\ ${ }^{5}$ Assistant professor, Department of Aeronautical Engineering, Hindusthan College of Engineering and Technology, \\ Coimbatore, Tamil Nadu, India
}

\begin{abstract}
The electric propulsion system of Unmanned Aerial Vehicles (UAV) is shifting from open propeller to the shrouded or ducted propeller due to its several advantages over open propellers. Numerous efforts and works have been made to improve the efficiency of the ducted propeller since its introduction in the 1930s. There was a significant increase in flight time due to increase in propulsive efficiency. One factor taken in consideration for overall efficiency of a UAV is its flight time. There has been much research and work on optimization of UAV to increase the flight time, either through minimizing the weight/introducing composite materials or by improving the efficiency of the electronic system or both. This work is an attempt to develop an onboard electricity generation system through an efficient duct equipped with a generator-turbine assembly. This is to increase the flight time without reducing the overall efficiency of the Unmanned Aerial Vehicle (UAV).
\end{abstract}

Keywords: Re-charging while flying, dynamo, ducted propeller, increased flight time, long range, high endurance, onboard power generation, increased overall efficiency and FM.

\section{INTRODUCTION:}

Duct is a shape which encloses the propeller by covering the circumference of the propeller to make the flow of air in a particular direction. In a single-ducted propeller, it increases the lift force production at a rate of $24.5 \%$ and $38.1 \%$ in FM efficiency as compared to the non-ducted single-propeller [4].

Duct eliminates the formation of vortices at the blade tips. It increases the thrust by reducing the losses occurring at the tip of the blade. Ducts are used to produce much more stability and reduce the wastage of thrust produced by the rotor. As the turbine situated under the motor also rotates, it does not bring the air to rest.

After the introduction of the turbine at the end of the duct, the thrust produced by the ducted propeller with the obstacle (turbine) would be nearly the same as that of the open propeller. If the thrust is not affected by the turbine, the flow around it can be converted to useful energy through a generator assembly connected to an electronic circuit on board.

The current generated is fed to a voltage regulator and then charged the battery through a charging circuit. Battery checker and temperature sensor are used to constantly check the battery voltage and temperature. As the drone is going to be used indoors, obstacle avoidance sensors are used. The battery will be recharged at a slow rate so the battery does not get damaged after many cycles of charging-discharging. So this can be very useful in the industrial applications and also for many indoor and outdoor purposes.

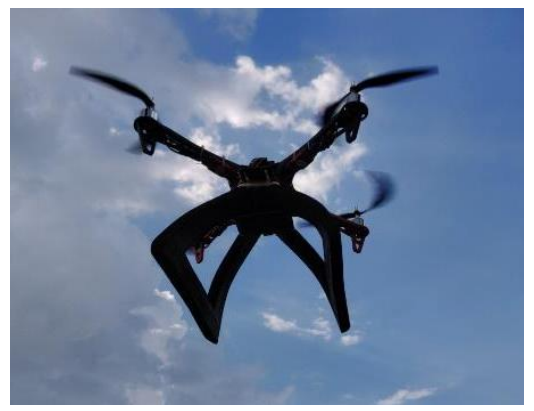

Fig1: An open-propeller UAV in flight 


\section{International Journal of Innovative Research in Electrical, Electronics, Instrumentation and Control Engineering}

Vol. 9, Issue 12, December 2021

DOI: 10.17148/IJIREEICE.2021.91206

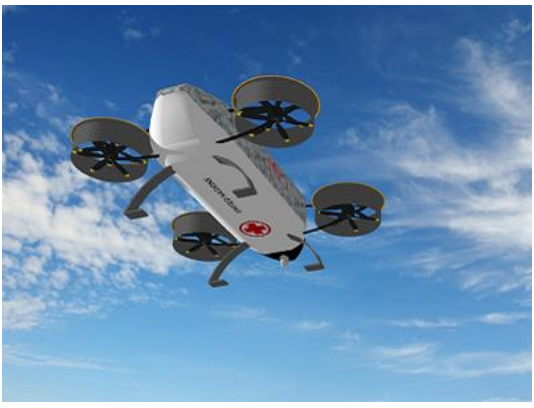

Fig2: A ducted-propeller UAV in flight

[Source: https://www.amatek.com/case-studies.html]

\section{PROPOSED SYSTEM:}

A rotorcraft (UAV) pushes air downwards to produce thrust in order to stay aloft. The magnitude of the thrust produced by an open propeller is increased by introducing a duct. The flow of air at the exit can be used to generate current to recharge the battery or use in other components onboard. An efficient nozzle has to be designed to have much higher propulsive efficiency than the open propeller to trade with a part of thrust to produce current. This proposed system will increase the flight time of the UAV, thus increase the overall efficiency and the figure of merit of the UAV.

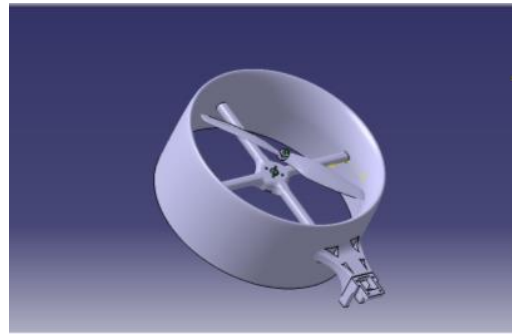

Fig3: CAD model of the duct for 8 inch propeller.

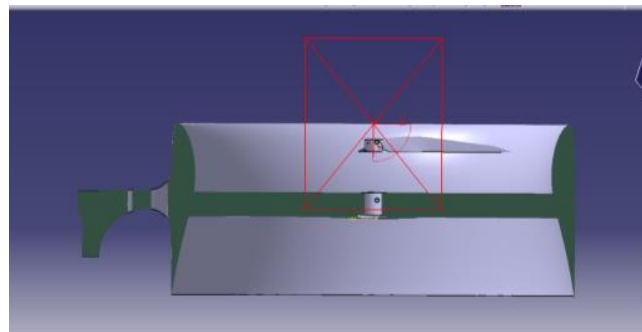

Fig4: Cut section of the ducted-propeller CAD model.

\section{MODEL DESCRIPTION:}

A duct is designed with the airfoil ah-80-140. The propeller is enclosed in the duct and is placed at a particular height of $0.3 \mathrm{H}$ of the total height $(\mathrm{H})$ of the duct from the inlet [12]. The duct is designed in a way to provide an adequate clearance at the blade tip of $0.1 \mathrm{~L}$ of the total diameter $(\mathrm{L})$ of the duct. The diffusion ratio of the duct is 0.5 to 1 . Diameter of the duct at $0.3 \mathrm{H}$ from the inlet is calculated to accommodate an 8 inch propeller having the above stated clearance. The support for the motors is provided from four sides of the duct to hold the motor rigidly. The generator and the turbine assembly is placed under the support of the motor in the same axis.

\section{PARAMETERS OF THE DESIGN:}

Clearance area: $0.1 \mathrm{~L}$ of the total diameter of duct $(\mathrm{L})$

Diffusion ratio: 0.5 to 1 for ducted propeller [13]

Placement of propeller in duct: $0.3 \mathrm{H}$ of the total height of duct $(\mathrm{H})$ from the inlet [12]

Gap between the propeller and turbine: It comprises the height of the motor, base/support and the generator. 


\section{International Journal of Innovative Research in Electrical, Electronics, Instrumentation and Control Engineering}

Vol. 9, Issue 12, December 2021

DOI: $10.17148 / I J I R E E I C E .2021 .91206$

\section{CIRCUIT DIAGRAM:}

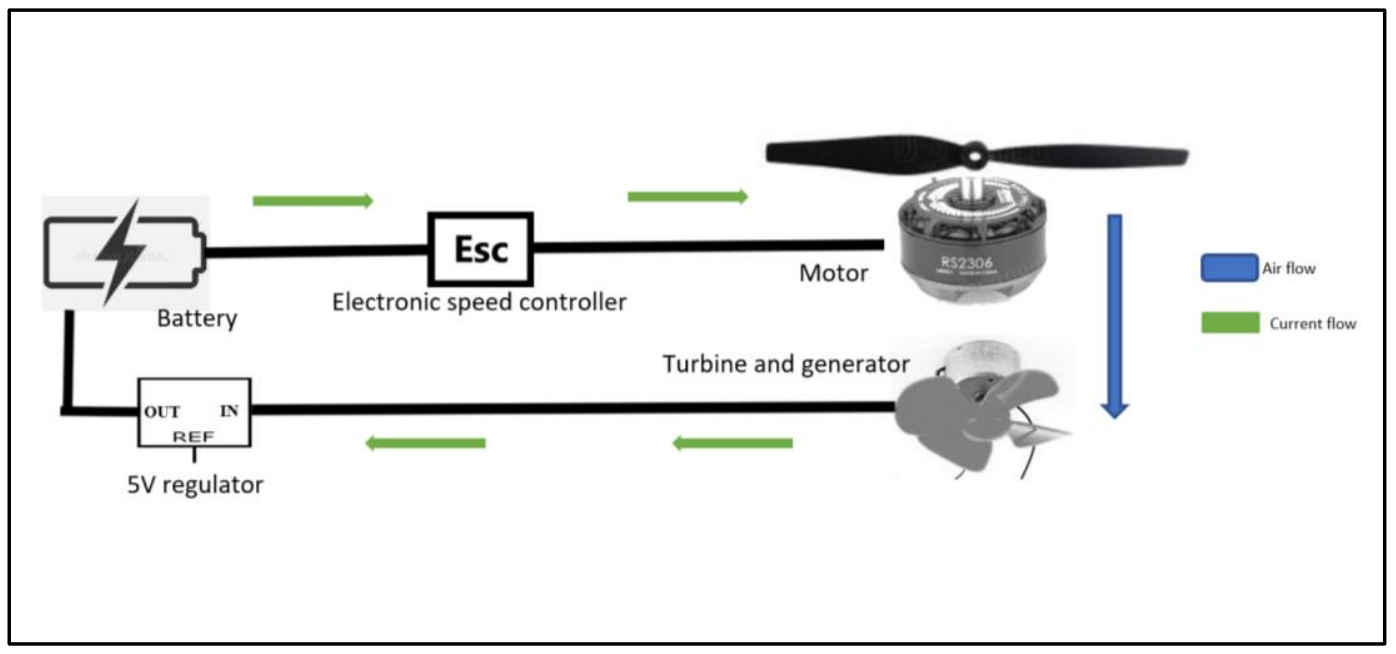

Fig5: Circuit diagram

\{Sources: Motor- [15], generator-[14], and propeller - [16]\}

\section{CONCLUSION:}

In this paper the advantage of the ducted propeller has been considered primarily to discuss the proposed concept of a system to use the thrust for propulsion as well as onboard generation of current to either recharge the battery or use to power other electronic components or both. The proposed system can be a major factor in the evolution of the Unmanned Aerial Vehicle (UAV) increasing the flight time, thus increasing the overall efficiency and figure of merit (FM).

\section{FUTURE WORK:}

Our research and work on this concept is in progress.

In future, this concept of propulsion cum power generation can also be equipped on fixed wing UAV which will be more efficient than a rotorcraft UAV.

\section{DECLARATION OF CONFLICTING INTERESTS:}

The author(s) of this paper declared no potential conflicts of interest regarding the ideas, concepts, design, research, authorship, and/or publication of this paper.

\section{REFERENCES:}

[1] Hongming Cai, Haisong Ang, Design And Analysis Of A Ducted Fan UAV, VIBROENGINEERING. JOURNAL OF VIBROENGINEERING. DECEMBER 2011, VOLUME 13, ISSUE 4, ISSN 1392-8716 (2011)

[2] Md. Shafayete Hossain, Md. Enamul Haque, Md. Rasedul Islam and Mohammad Mashud, Design And Development Of Ducted VTOL UAV, International Conference on Mechanical Engineering and Renewable Energy, ICMERE2015-PI-228 (2015)

[3] Robert J. Weir, Ducted Propeller Design and Analysis, SANDIA REPORT, SAND87-2118.UC-32, Printed October 1987

[4] Yi Li, Koichi Yonezawa and Hao Liu, Effect of Ducted Multi-Propeller Configuration on Aerodynamic Performance in Quadrotor Drone, Drones 2021, 5, 101. https://doi.org/10.3390/drones5030101

[5] Nijandan S, Gokulakrishnan G, Nagendra Prasad R, Mr. Mahendran S, Mr .P. S. B.Kirubakaran, Autonomous Onboard Power Generation System in UAVs for Long Range, (IJERT) ISSN: 2278-0181 IJERTV4IS020576, Vol. 4 Issue 02, February-2015

[6] Mohammad Murshadul Hoque, Design, Implementation And Performance Study Of Programmable Automatic Voltage Regulator, J. Electrical Systems 10-4 (2014): 472-483

[7] Dimitrios Rimpas, Athanasios Kiatipis, Charging Strategy Effect On Lithium Polymer Battery Capacity: A Case Study, International Journal Of Energy And Environment, Volume 11, Issue 2, 2020 pp.107-118

[8] Stefano Gaggero, Cesare M. Rizzo, Giorgio Tani, and Michele Viviani, EFD and CFD Design and Analysis of a Propeller in Decelerating Duct, Hindawi Publishing Corporation International Journal of Rotating Machinery, Volume 2012, Article ID 823831, 15 pages doi:10.1155/2012/823831

[9] Weikang Du and Spyros A. Kinnas, Optimization Design and Analysis of Marine Ducted Propellers by RANS/Potential Flow Coupling Method, International Society of Offshore and Polar Engineers, (ISOPE) ISBN 978-1 880653 85-2; ISSN 1098-6189 


\section{International Journal of Innovative Research in Electrical, Electronics, Instrumentation and Control Engineering}

Vol. 9, Issue 12, December 2021

\section{DOI: $10.17148 / I J I R E E I C E .2021 .91206$}

[10]Abolfazl Halvaei Niasar, AmirHossein Sabbaghean, Design And Implementation Of A Low-Cost Maximization Power Conversion System For Brushless Dc Generator, Ain Shams Engineering Journal (2017) 8, 571-580

[11]Anwar MN Malgoezar, Ana Vieira, Mirjam Snellen, Dick G Simons and Leo LM Veldhuis, Experimental Characterization Of Noise Radiation From A Ducted Propeller Of An Unmanned Aerial Vehicle, International Journal of Aeroacoustics 2019, Vol. 18(4-5) 372-391

[12]S. Yilmaz, D. Erdem, M.S. Kavsaoglu, Performance Of A Ducted Propeller Designed For Uav Applications At Zero Angle Of Attack Flight: An Experimental Study, JID: AESCTE AID:3343 /FLA, Published by Elsevier Masson SAS 2015

[13]Endrowednes Kuantama, Radu Tarca, Quadcopter Thrust Optimization With Ducted-Propeller, MATEC Web of Conferences 126, 01002 (2017), DOI: 10.1051/matecconf/201712601002, Annual Session of Scientific Papers IMT ORADEA 2017

[14]Source1:https://robu.in/product/micro-motor-wind-turbine-generator-dc-power-diy-0-1v-18v2006000rpm/?gclid=CjwKCAiAh_GNBhAHEiwAjOh3ZFPR6AGat7ff1wL5t4dgJv1gXDF0LH8FH-oKrF6aQNzqYwC7SatVBoCDEgQAvD_BwE

[15]Source2:https://www.google.com/url?sa=i\&url=https\%3A\%2F\%2Fcommons.wikimedia.org\%2Fwiki\%2FFile\%3AVoltage_Regulator.svg\&psig =AOvVaw0I05rYPuGQD9XQe6R0_tuQ\&ust=1639892847833000\&source=images\&cd=vfe\&ved=0CAsQjRxqFwoTCLiNpNnb7PQCFQAAA AAdAAAAABAD

Source3:https://www.electronicscomp.com/emax-black-rs2306-2400kv-bldc-fpv-racing-motor?gclid=CjwKCAiAh_GNBhAHEiwAjOh3ZMU3311wOPVDJPjrC4BHcZj-s9aNhOvbHjBUSR6kvO7JB6gLII6QRoCoGMQAvD_BwE 